\title{
AS RESISTÊNCIAS AFRICANAS DIANTE DAS MEDIDAS PREVENTIVAS COLONIAIS CONTRA A DOENÇA DO SONO NA ZÂMBIA (1890-1920)
}

\author{
Jefferson Olivatto da Silva ${ }^{1}$
}

\begin{abstract}
RESUMO
A dinâmica colonial pode ser entendida como reflexo de processos imperiais e reações populacionais oriundas de práticas culturais anteriores. Para além de um olhar de vitimização o qual as populações africanas foram reduzidas, houve resistências que não foram apreendidas pelas autoridades estrangeiras e por isso se desdobraram no cenário colonial. Para colaborar com a investigação da dinâmica colonial fizemos uso da interface entre Antropologia da Saúde e História da Medicina em África acerca da ênfase dada a descoberta e controle da doença do sono (tripanossomíase humana africana), no norte e oeste da Zâmbia, de 1900 a 1920. Com efeito, chegamos à composição de um esquema interpretativo baseado em três dimensões: ecológica, medicina tropical e operacionalizações africanas, definindo as ações africanas enquanto atitudes elusivas: ações políticas específicas desdobrando resistências às imposições das políticas coloniais.
\end{abstract}

Palavras-chave: Medicina Tropical, Práticas culturais, Zâmbia, resistência.

\begin{abstract}
Title: African resistances relating to colonial preventive measures on sleeping sickness in Zambia

Colonial dynamics can be understood as a response between imperial processes and people's reactions according to later cultural practices. Beyond reducing African people victimization, there were resistances
\end{abstract}

1 Artigo tecido a partir do estágio de pós-doutoramento na Universidade Federal do Paraná, com fomento do Convênio CAPES/Fundação Araucária. Devo agradecer as contribuições e apoio da supervisora, Profa. Dra. Marionilde Dias Brepohl Magalhães e a permissão de consulta nos arquivos portugueses: Instituto de Investigação Científica Tropical, Instituto de Higiene e Medicina Tropical e Sociedade de Geografia de Lisboa. 
not apprehended by foreigners' authorities, developed along with colonial policy. Our methodology was an interface between Anthropology of health and History of medicine in Africa related to the discovery and control of sleeping sickness (human African trypanosomiasis), in Northern and East Zambia - 1900 through 1920. Thus we elaborated an interpretative scheme based on three dimensions: ecology, tropical medicine and African operationalizations. As a result we came to define African actions as elusive attitudes: special political actions developing resistances to the colonial policy impositions.

Keywords: Medina tropical, práticas culturais, Zâmbia, resistência. 


\section{Introdução}

Nosso artigo procurará contribuir com o entendimento das respostas sociais às medidas preventivas desenvolvidas na África Central pela Medicina Tropical. Esta área surgiu compassada com os interesses de exploração colonial quando adentraram ao continente africano no final do século XIX. Os médicos trouxeram novos interesses que disputavam no campo simbólico com autoridades coloniais, empresas de prospecção e religiosos.

Nosso recorte será o de especificar as medidas preventivas adotadas com relação à tripanossomíase africana ou doença do sono, que deslocaram populações de seus vilarejos para contê-los em campos de isolamento próximo ao rio Kalungwishi, Luapula, no norte da Rhodésia do Norte (Zâmbia), governada pela British South Africa Company (BSAC) e outro campo próximo ao Forte Jameson, hoje Chipata (fronteira com Malauí), que antes era governada pela African Lake Company (ALC) passando ao auspício da primeira. Da interação de três dimensões - ecológica migratória, medicina tropical e práticas culturais - propomos a interpretação do que chamamos de atitudes elusivas, que observamos ocorrer uma lógica específica de resistência populacional a determinadas políticas coloniais.

Para tanto, as escolhas de objetos e a complexidade segundo as dimensões aqui apresentadas abrange a lógica constitutiva das ações africanas do início da colonização do interior africano desdobradas até às vésperas da I Grande Guerra Mundial. Nossa hipótese corrobora a de Maryinez Lyons (1992) apresentada em The colonial disease: a social history of sleeping sickness in northern Zaire 1900-1940 e Megan Vaughan (1991), Curing their ills: colonial power and African illness, de que a colonização em suas diferentes frentes, com o auxílio da Medicina Tropical, se chocaram com as formas de manutenção de cuidado coletivo das populações locais, a ponto de criarem uma recusa em larga escala aos tratamentos atuais 
de Síndrome da Imunodeficiência Adquirida (SIDA), tuberculose (TB), tripanossomíase humana, malária, cólera, tifoide, hanseníase entre outras.

As doenças tropicais se posicionaram como um dos fatores que dificultaram a exploração da força de trabalho e das riquezas naturais como esperado pelas potências imperiais. Além disso, o cotidiano africano distava da concepção de normalidade mental e higiênica do hemisfério norte ocidental. Manifestações corporais e estados psicológicos desconhecidos não correspondiam aos diagnósticos clínicos ocidentais, corroborando o etnocentrismo sobre a alteridade africana, que pelo discurso biomédico, tornou-lhe uma natureza doentia (VAGHAN, 1991).

Para compreender a composição das respostas africanas a partir da introdução da medicina ocidental, deslocaremos o discurso de vitimização africana para o comportamento social africano como alusão a um tipo de ação social e política específica. Frisamos utilizar no texto África Central como categoria socioespacial que abrangerá igualmente as regiões da Zâmbia e Malauí, por conta da perspectiva que adotamos para explicar a importância ecológica dos laços migratórios, que abarcam as regiões desde o oeste do lago Tanganyika até o do Niassa.

Outrossim, os grupos populacionais africanos que foram narrados e descritos pelo grupo católico, Missionários da África, também orbitaram pela categoria de grupo-modelo ao qual às missões cristãs, católicas e reformistas, utilizavam-se em sua estratégia de conversão (KALINGA, 1985; IPENBURG, 1992). À medida que o grupo dominante fosse convertido os grupos tributários acompanhariam a formação do campo católico. Algo que pode ser observado em Buganda na corte do kabaka Mutesa (Mteça) ou pelos boêres da Dutch Reformed Church com os Angoni na Niassalândia (Malauí). Por isso, a escolha de um grupo-modelo pode ser entendida como o campo da esfera simbólica estrangeira sobre as populações 
locais (KALINGA, 1985). A título de exemplo, as narrativas desses missionários expandem a órbita de vínculos e trocas simbólicas dos Babemba $^{2}$ : missionário Foulon, Les Bemba, s/d, apresentou costumes e desenhos sobre objetos de uso cotidiano, com descrições entrecortadas sem preocupação com um discurso uníssono; missionário Garrec, Lubemba of the years 1910-1920 seen through the writings of Fr Garrec WF, 1910-1920 (?) e missionário Edouard Labrecque (1982), Customs of the Babemba and neighbouring tribes ( $/ d$ ); Beliefs and religious practices of the Bemba and neighbouring tribes (escritos no período de 1931 a 1934).

\section{Colaborando com a investigação}

De certa maneira, para que as respostas das comunidades zambianas sejam destacas das narrativas estrangeiras, precisamos de uma perspectiva a partir dos vencidos ou dominados, como feito por James Scott (1985) ao interpretar as ações de riso e anedota como o registo escondido ou formas cotidianas de resistência, traduzidas como silêncio dos vencidos por Edgar de Decca (1997); já Franz Fanon em Máscaras brancas e peles negras (2008) explica o processo imagético dos colonizadores brancos e dos colonizados negros, tendo a correspondência imaginária da mimésis como via para os negros minimizarem sua alteridade depreciada; e Néstor Garcia Canclini (2010) demonstrou como as camadas populares encontraram novas formas de resistência, como anedotas, pichações e história em quadrinhos, nomeando-as de poderes oblíquos.

Embora se pode argumentar que não ocorre uma transformação social por essas vias, o que ocorre são táticas para manter o poder de determinados vínculos culturais e afetivos e assim resguar-

2 Usaremos Bemba como adjetivo de um grupo e Babemba como população. Para uma melhor abrangência dos discursos dos Missionários da África sobre os Babemba ver o artigos 2011 e 2013. 
dar traços e dinâmicas identitárias contra a supressão sofrida dos grupos dominantes. Expandimos para nosso propósito a concepção de vulnerabilidade por uma fronteira espaciotemporal de longa duração, nesses termos: primeiro, foi distante de um evento acidental, temporário ou isolado, que possibilitaria aos indivíduos recursos sociais para reestabelecer o domínio de sua condição humana anterior, longe da exploração e domínio estrangeiro de seu corpo; segundo, trata-se de um enfoque sobre a exclusão social relativa a longos períodos e durante várias gerações que tiveram reduzido seu direito ao espaço coletivo e público para espontaneamente manifestar vínculos afetivos e culturais, na mesma proporção que lhes tiraram o direito às condições objetivas socioeconômicas ${ }^{3}$ de se afastarem de represálias ou desprezos etnocêntricos. Corresponderia tal vulnerabilidade à exclusão de longa duração, e não relativa a um evento esporádico ou acidental ou geracional. A linha para constituirmos essa forma de investigação, distintamente, seria por um caminho sócio-histórico sobre os desdobramentos dos comportamentos sociais diante da negligência hegemônica e absoluta que pairou sobre os primeiros habitantes locais (DA SILVA, 2012b; NASCIMENTO; MARTORELL, 2013).

Compreendemos que as diferentes reações das populações foram se desdobrando mediante posicionamentos assimétricos de poderes estrangeiros não legitimados pelas estruturas sociais locais, como foi o caso da exploração pré-colonial e colonial na África Central. Além disso, esse processo esteve vinculado às gerações que conviveram com a exploração social pressionando seu apagamento cultural público. Como expressão desse embate foi necessário instrumentalizar determinados comportamentos em uma lógica social de perpetuação identitária. Por meio de determinados signos culturais - artefatos, expressões corporais e falas - os atores rebatiam as im-

3 Discutimos essa questão sobre a relação entre vulnerabilidade e autonomia em outro artigo (DA SILVA, 2012) 
posições estrangeiras para proteger o aniquilamento de seus vínculos afetivos. Como esses signos não eram compreendidos como forma de poder e, por isso, desprezados como alteridades subalternas pelas autoridades coloniais, as populações conseguiram multiplicá-los e perpetuá-los diante da imposição de novas medidas de controle social.

A credibilidade dos vínculos afetivos modelou o comportamento social para resistir à sobrecarga de sofrimento coletivo. Nesse sentido, esses laços correspondiam à proximidade entre consanguíneos, correlatos, chefes e súditos ou pares, que partilhavam situações similares de tensão social. A credibilidade e a eficácia das atitudes dependeram da dinâmica desse convívio, que impulsionava sua reprodução e sua alteração em várias gerações. Por isso, de acordo com o interesse dos membros dos grupos locais, viam no distanciamento criado por papeis sociais de assimilados - como religiosos, catequistas, mensageiros coloniais, soldados e professores - outra forma de lidar com o poder exploratório e colonial. Conquanto eles agissem mimeticamente com os estrangeiros na posição de elite local para diminuir os traços identificadores de sua alteridade, a tensão social aparentava ser minimizada; porém tal esforço era efetivo se manifestasse o desprezo latente dos exploradores a algumas das manifestações culturais locais, enaltecendo as estrangeiras. Diante do espaço social partilhado ou dominado pelo estrangeiro, como escolas $^{4}$, igrejas, hospitais e espaços administrativos, algumas demonstrações culturais eram expurgadas tornando-se quase invisíveis, isto é, escondidas e não ditas; enquanto no espaço social e momentos

4 As escolas missionárias eram internatos, assim como outras instituições administrativas coloniais que permitiam a aprendizagem do controle social colonial e vias de expressão com menor tensão. Podemos observar que em algumas situações como apresentada por Hunt, em Colonial Lexicon of birth medicalization, and mobility in the Congo, 1999, na forma de brincadeira aceitável, como a inversão de papeis durante o almoço de Natal, os adolescentes e jovens como patrões momentâneos manifestavam abertamente o desprezo pelos trabalhadores locais pelo convívio com a elite colonial. 
resguardados aos locais esses traços culturais eram manifestados e perpetuados como signos identitários. Circunstâncias dominadas pela população feminina, como no caso da iniciação feminina, $C h i$ sungu, operavam sem o controle externo; a ponto de o missionário J.J. Corbeil (1982) descrever na introdução de seu livro, Mbusa: sacred emblems of the Bemba, que em 1960 pressionou uma senhora de nome Helena, do vilarejo real de Mubanga, Distrito de Chinsali, para que revelasse esse ritual como condição para ser readmitida ao catolicismo, depois de ter participado por um tempo da Lumpa Church de Alice Lenshina Mulenga.

Outros rituais intensificavam traços dos vínculos populacionais a ponto de lhe ser protegido por uma fronteira de mistério ou oculto. $\mathrm{O}$ aspecto oculto pode ser observado principalmente nos estudos sobre a bruxaria (COMAROFF; COMAROFF, 1992), como uma atitude proscrita anterior à colonização. A morte e doenças seriam causadas pelo poder incontrolável de uma bruxa ou bruxo, quer o ator tivesse ou não consciência de suas ações. Já o mistério protegeria um poder cercante de produções sociais ritualísticas, qual seja, sua realização fugia ao alcance do controle dos estrangeiros, como as iniciações femininas e arenas de parturição. Para Nancy Hunt (1999), as salas de parturição coloniais estavam revestidas por auras de sigilo, por isso ela pede ao historiador cautela quanto ao peso das informações obtidas, quer textuais ou orais, se não foram reduzidas ou editadas pela competição colonial por conhecimento, rumor ou camuflagem. No contexto vitoriano das colônias detalhes sobre a parturição eram apagados das fontes até o final dos anos de 1950. Ademais, a interpretação dos parentes sobre os instrumentos utilizados durante o parto e detalhes dos procedimentos dos partos conduzidos nos vilarejos eram resguardados do desprezo colonial a tudo o que era considerado superstição ou fetichismo.

Com efeito, queremos demonstrar que o não reconhecimento do comportamento social zambiano como poder compartilhado entre 
a população colonizada respondeu por sua perpetuação no cotidiano africano como ação política de tipo específico, já que para os administradores, coletores de impostos, militares, missionários e médicos era entendida como manifestações de esquiva pertencentes a um universo desprezado sem função social significativa.

\section{Intercâmbio entre as dimensões}

Precisamos de início apresentar nossa proposição sobre o intercâmbio dessas dimensões delimitadas pelo processo colonizador por suas ações de expropriação de bens materiais e imateriais, apropriação desses bens para diferentes fins, como de construção de museus e zoológicos, e exterminar pelo desprezo bens orgânicos (fauna, flora e humanos) que caracterizou a exploração pré-colonial e colonial.

De acordo com Jürgen Osterhammel (2005), o colonialismo precisa ser entendido de acordo com os interesses exploratórios regionais: o tipo africano ocorreu pelo uso da força de trabalho tão somente nativa; o tipo caribenho dependia de escravos comprados da África; e o da Nova Inglaterra destituía e aniquilava as populações nativas para a ocupação. O tipo de influência exercida sobre as colônias britânicas, como ocorrido na Zâmbia e Malauí, foi o de Carta Régia para inicialmente explorar e se comprometer em ocupar, por aquilo que o autor pressupunha ser os dois propósitos dos regimes coloniais - manter a ordem e possibilitar que empresas e investidores pudessem extrair dos recursos da região - o papel dos agentes, por exemplo, McKinnon diante da BSAC era o de viabilizar terras para a exploração, cobrar impostos e apaziguar quaisquer insurreições das populações, que de início era a resistência dos Babemba ao domínio estrangeiro.

Passaremos agora a descrever o espectro das dimensões para esclarecer a respeito da lógica de resistência zambianas 
operadas em Kalungwishi e Forte Jameson, como os centros de isolamento para o tratamento da tripanossomíase, de acordo com Mwelwa Musambachine (1981).

Os movimentos migratórios das populações da África Central podem ser constatados por indícios materiais e ideológicos conectados pela tradição oral. Tomaremos por base as pesquisas de Jan Vansina $(1966 ; 1985 ; 1990)$, que tem sido citadas e referenciadas por outros africanistas - Boahen, Ogot e M'Bokolo - sobre a região.

Várias populações migrantes da atual República Democrática do Congo (RDC) para Zâmbia - Luvale, Ndembu, Kazembe, Bemba entre outros - operam sua gênese como parte da expansão dos impérios Lunda e Luba. O império Luba teria se constituído de populações de Shaba e Kasai, enquanto o Lunda, principalmente, dos Rund, além de Ndembo, Lozi, Imbangala entre outros. O império Luba teria se originado por meio das pequenas chefarias na Depressão Upemba, entre as poucas regiões de solo fértil dentro de um vasto território inabitado, por volta do século XIII. Já o reino Rund não pode ser remetido antes de 1680 (OLIVER; ATMORE, 2001; VANSINA, 1985; 2006). Outro indício de distinções entre os dois impérios, que apenas tardiamente teria estabelecido um convívio mais intenso, é ilustrado pela classificação linguística feita por M. Guthrie sobre o desenvolvimento das línguas subsaarianas. As línguas de ambos os impérios está classificada pela letra L e, no interior desta, as línguas Luba pertenceriam ao grupo 50 e as Lunda ao grupo 30.

Outro indício material de intenso contato entre as populações pode ser observado como resultado de interesses comerciais - a comercialização de sal, óleo de palmeira e ráfia teriam criado elos entre as populações circundadas pelos lagos Tanganyika, Niassa, Mwero e as populações da Depressão Upemba - cuja moeda corrente fora as cruzes de ferro, desde o século XIII (VANSINA, 1990; M'BOKOLO, 2007). Porém com sua desvalorização no século XVII, pelo intenso uso e seu tamanho ser reduzido, houve sua substituição por pérolas 
no século XIX. É possível considerar que a valorização dessas contas tenha ocorrido pela influência das caravanas comerciais árabes no interior africano, de ambas as costas, podendo ser observado pelo empréstimo do sistema numérico Swahili, originário da costa leste, no interior dos sistemas numéricos das populações desde Uganda até as da África do Sul (DA SILVA, 2012). Dentre as personalidades árabes da segunda metade do século XIX, Tippo Tipu foi o mais renomado comerciante que estabeleceu postos no interior do Congo, em direção à costa leste, e auxiliou exploradores como Henry Stanley, quando procurava por David Livingstone (RENAULT, 1992). Henri Scott (1947) atribui as caravanas de Stanley a introdução da tripanossomíase no interior do Congo, em 1887, na tentativa de resgatar também Emin Pasha, ou a caravana deste médico naturalista do Congo até Uganda. Embora seja difícil de verificar, corrobora o pensamento de Lyonz sobre o surgimento de surtos epidêmicos até Uganda (1992).

Conforme as chefarias foram se estruturando, a chegada dos árabes e suas rotas influenciaram a tendência à patrilinearidade na organização das sociedades, porém muitas mantiveram a matrilinearidade. Nesse processo o culto aos antepassados como nsiri teria aumentado esse poder em torno dos chefes homens, algo que pode ser observado no século XIX pela expansão Bemba, que suprimiu o culto feminino aos antepassados dos primeiros habitantes suplantado pelo culto aos chefes, mipashi (RICHARDS, 1956; RASING, 1994). Como originários da expansão Lunda, os Babemba têm similaridades em sua estrutura social na forma de organização militar como os Maravi, Undi e Kazembe, retratando essa provável origem comum (EPSTEIN, 1975).

As trocas simbólicas entre as populações da África Central instituíram na manutenção social a iniciação de jovens, meninos e meninas. Tanto que Richards (1956) apontou haver entre as populações de Angola a Moçambique, uma extensa similaridade entre a iniciação feminina ao que ela pesquisou na Zâmbia, chamada de Chisungu. 
Como observamos pelas pesquisas de Olivier Gosselain (1999) sobre as técnicas da produção de cerâmicas em 102 grupos, houve uma contínua comunicação entre as populações segundo uma lógica termodinâmica, conforme a posição de De Heusch (1972; 1982) e Gausset (1992). A pesquisa de Gosselain (1999) demonstra essa correspondência simbólica na produção das cerâmicas em uma vasta região, que compreende desde os Serer no extremo oeste do Sahel até os Zulu na África do Sul. Essa lógica perpassaria atividades de iniciação, preparação de alimentos, caça e guerra, como também gêneros, sons, objetos, animais e doenças classificando-as de quentes ou frias. Nesse sentido, algumas doenças, como a hanseníase, seriam o resultado de um duplo aquecimento (doença e hanseníase) por ser julgada como uma doença solar que queima a pele. De outra maneira, no interior dessa mesma lógica que residiria a razão de ser para os Babemba afirmarem que quando o chefe mantém relações sexuais ele aquece o solo e quando morre o solo se torna frio, isto é, infértil (LABRECQUE, 1982).

Foi o vínculo com a expansão Lunda que determinadas chefarias se estabeleceram ao longo de toda a extensão norte da Rhodésia do Norte e Niassalândia, como Chokwe, Luvale, Lozi, Ndembo. Kazembe, Bemba e Maravi. Todavia foi sua organização militar que auxiliou a esses antigos tributários o domínio das primeiras populações. Se compararmos com as rotas árabes e Swahilis, há uma correspondência entre o estabelecimento dessas chefarias, o que pressupõe ter ocorrido um interesse dessa localização por parte dos generais de Lunda para o fortalecimento do império. Os chefes Kazembe derrotaram os chefes de Luba em Luapula e tomaram a frente do interesse comercial da costa pelos portugueses, foram a Sena e Tete estabelecer contato. A chefaria de Kazembe conseguiu impressionar as missões portuguesas - Francisco Almeida e Lacerda em 1798-1799 (PEREIRA; RIBAS, 2012), Monteiro em 1831-1832 e recontada por Gamitto em 1854 (CUNNISON, 1960) e Serpa Pinto de 1877 a 1879 (SERPA PINTO, 1881). Pelo aumento da procura 
de marfim, pedras preciosas e escravos na costa Índica, os postos comerciais árabes e Swahili a partir de Kazembe instituíram postos para o fluxo mercantil se bifurcar para o norte e para o sul do Lago Niassa. Esses postos contavam com a participação de chefes locais, assegurando benefícios com os bens estrangeiros, como tecidos e armas, para se imporem a outros clãs em troca de marfim, ouro e escravos (ROBERTS, 1973).

A ênfase dos Missionários da África por seu grupo-modelo da Rhodésia é explicado pelo vínculo histórico iniciado pelo Monsenhor (Mgr.) Joseph Dupont e o chefe supremo Bemba, Chitimukulu Sampa, durante o processo de sua rendição ao domínio britânico da British South Africa Company (BSAC). Como o Chitimukulu já tinha sido derrotado em batalhas contra o exército alemão de Herman von Wissmann (1853-1905) que minara a resistência Bemba em Ufipa (MPONDA-MAMBWE 1891-1895, p. 41; ROBERTS, 1973), seu poder diante dos seus sub-chefes estava enfraquecido. A aceitação da entrada de Joseph Dupont em seu território corroborava com sua pretensão de domínio. Porém nem todos os subchefes concordaram com o Chitimukulu acusando-o de serviçal dos brancos (ROBERTS, 1973). Mas após a morte deste, todos passaram a dialogar com McKinnon para o processo de sucessão e pacificação (pax britannica).

Se considerarmos a chegada dos exploradores e mercadores ocidentais no interior africano, as rotas das caravanas podem demonstrar a força militar, que fizeram com que chefes oferecem seus tributários para o carregamento de mercadorias, visto que ficariam afastados da produção de sal, de alimentos e de sua própria defesa contra outros invasores. Nos diários do posto de Mambwe dos Missionários da África, observamos reclamações por parte desses atores religiosos o constante trânsito comercial, na Estrada de Stevenson, conectando o porto ao sul do Lago Tanganyka ao norte do Lago Niassa, posto que as populações se ausentavam, em muitos casos, 
definitivamente - alguns depois da entrega do carregamento eram vendidos como escravos. Como aparece no diário dos Missionários da África, Mponda-Mambwe, 1891-1895, p. 37, o oficial Bainbridge, em 27 de abril de 1893, passara por Mambwe, vindo de Ujiji, com uma carga pesando 4.000 libras de marfim tendo deixado para traz em Kituta 10.000 libras. O resultado era a falta de uma população fixa para a evangelização. Entender que essa ação era compulsória deve significar como imposição dos comerciantes das empresas coloniais sobre os chefes e da situação de vulnerabilidade que determinados grupos se encontravam por falta de vínculos satisfatórios.

Somando-se às mobilidades, outros interesses começavam a surgir em torno dos postos missionários: busca por alimentos nos períodos de estiagem ou por cuidados de saúde, fugas de invasões de vizinhos ou exércitos ou ataques de feras. Grandes distâncias entre chefes e populações nos vilarejos e o enfraquecimento da distribuição de poder entre os súditos tornavam atrativos os postos dos estrangeiros.

Com efeito, sem uma tônica de homogeneização entre os grupos africanos, esses indícios de partilha demonstram o quão presente era a circulação de diferentes interesses que gradativamente se inseriram no cotidiano. De uma forma mais abrupta esse cenário foi alterado no século XIX. As potências europeias ansiando novas fontes de riquezas investiram na exploração do interior africano. Isso proporcionou novas migrações por efeito cascata com diferentes motivos: fuga do trabalho forçado no Congo ou escravidão árabe, apropriação de terras férteis e aquíferos por autoridades boêres na África do Sul e alemães na Namíbia, chegada de colonos e instalação de fazendas no Zimbábue, assim como a prospecção de minérios e construção de estrada de ferro para o escoamento desses produtos. Para termos uma noção desse projeto de escoamento, as estradas de ferro que ligava Cape Town (África do Sul) a Bulawayo (Malauí) foram completadas em 1897, a que ligava o Copperbelt (Congo/ Zâmbia) a Benguela (Angola) foram finalizadas em 1931. 


\section{Desenvolvimento da Medicina Tropical}

Segundo Michael Worboys (1989), na virada do século XIX para o XX, a Medicina Tropical ainda como uma especialidade de pós-gradação era uma área procurada por médicos ambiciosos em suas carreiras, a ponto de $20 \%$ dos britânicos graduados em Medicina se enveredarem nas colônias tropicais e subtropicais, acompanhando as forças armadas coloniais.

Os discursos sobre a Medicina Tropical referente às colônias não correspondiam aos modelos e tratamentos similares ocidentais. De outra forma, os traços da saúde normal das populações das metrópoles estavam distantes da saúde dos africanos (VAUGHAN, 1991). Primeiro o cotidiano africano era modelado por concepções evolucionistas lineares, civilizatórias e salvacionistas. Esse cotidiano compunha o cenário social, ecológico e de interesses onde estavam dispostos determinadas resoluções a seus conflitos. Com efeito, independente da ausência biológica de parasitas, havia tratamentos disponíveis para sua natureza colonial - desprezada pelo entendimento colonial por signos de selvageria, fetichista e ingênua.

Como afirmou Rosenberg (1992), a doença, disease, é uma entidade elusiva por lidar com uma realidade complexa: construtos verbais que refletem a história médica intelectual e institucional, uma oportunidade de legitimar a política pública, referente ao papel social ocupado por um indivíduo reafirmando sua identidade, uma forma de sancionar valores culturais e um elemento estruturante na interação entre médico e paciente.

Charles Rosenberg (1992) buscou explicar as epidemias em decorrência de duas tendências competitivas: a doença como causa externa ou interna ao organismo humano. De outra forma, havia a tensão entre as tendências de contaminação ou configuração. Essas pressuposições que ora se alternavam ora se complementavam eram 
anteriores a qualquer noção de agentes infecciosos. Sem por isso desaparecerem por completo nas explicações atuais. O ponto de vista da configuração compreendia a doença no interior de uma noção holística e inclusiva, isto é, devido a uma forma particular de configuração de circunstâncias, como um distúrbio da normalidade de ajuste de clima, ambiente e vida comum, as explicações médicas nomeavam as epidemias. A seu turno, a saúde seria como um equilíbrio balanceado e os valores impressos na relação entre a humanidade e seu meio ambiente como um bloco coeso. Já a contaminação tem em seu bojo a noção de contágio de pessoa para pessoa, de um elemento mórbido transmitido entre as pessoas. Enquanto a configuração enfatiza a interconexão, o equilíbrio ou o sistema, a contaminação apoia-se sobre um elemento particular desordenante. Outrossim, um terceiro elemento surgiu como apoio às duas tendências, a predisposição. Como aponta Rosenberg (1992), a predisposição constituiu uma ponte lógica e emocional para explicar, quase que satisfatoriamente, o motivo para que alguns sucumbem às doenças e outros saem ilesos.

Seguindo uma concepção de configuração, para Marinez Lyons (1992), foi o rápido contato entre populações costeiras com as do interior gerados pelas rotas e interesses comerciais que explicaria o aparecimento das epidemias africanas. Uma das explicações seria o repentino convívio entre parasitas e organismos humanos ocasionando o adoecimento de um grande número populacional. $\mathrm{O}$ argumento ecológico nos leva a entender que se houvesse um período significativo desse encontro, anterior a chegada das caravanas, é muito provável que ambos os organismos já estariam em certa homeostase, isto é, uma situação endêmica. Visto assim, a violência dessas ocupações deteriorou concomitantemente a relação ecologia-vida social, conforme uma perspectiva sistêmica.

Nesse aspecto, missionários e médicos concordavam que a aglomeração de pessoas nas urbes favoreceu o avanço das epidemias na África. Porém, devemos entender que para eles tanto a 
doença humana quanto a animal na África integravam um ambiente subestimado que precisava ser conquistado e controlado, ao que corrobora os anseios colonialistas de explorar como meio de civilizar, descrito por John MacKenzie (1984), em Propaganda and Empire: the manipulation of British Public Opinion, 1880-1960. Por isso, o argumento da predisposição era profícuo para agregar interesses exploratórios na África.

Cada epidemia apelava para interesses específicos, até competitivos. A febre amarela que atingiu a Philadelphia em 1793 pressupunha haver uma "transportabilidade" entre a chegada de navios oriundos de portos infestados com a febre. Para os contagionistas a população era infectada por essa morbidade devido à falta de limpeza de seu ambiente. Enquanto a tifoide por explicações menos polarizadas estava associada à fome, às regiões populosas, sujeira e pouca ventilação, como seguia sua nomeações comuns: febre de campo, febre de cadeia e febre de navio.

A teoria do germe foi resultado de uma medicina mais instrumentalizada em busca de uma causalidade não holística ou ambiental, como o era a teoria miasmática ou atmosférica. Essa depositava sobre condições de sujeira, e diretamente, das urbes a causa das epidemias, vinculando-se sobremaneira a vida cosmopolita cuja dinâmica social possibilitaria a comportamentos imorais. Pela descoberta do agente causador da tuberculose (TB) por Robert Koch, em 1883, a opinião médica foi dirigida para a concepção moderna de contaminação por sua orientação laboratorial. Todavia essa nova teoria não baniu a tendência holística, mas constituiu uma nova tensão: teoria do germe versus teoria miasmática (ROSENBERG; GOLDEN, 1997).

Se a varíola (LÉPINE, 2000) e a cólera (ECHENBERG, 2002) foram transportadas facilmente pelos navios, atingindo o cotidiano das Coroas, a tripanossomíase africana ou doença do sono significou uma barreira à exploração absoluta da força de trabalho 
africana. Por meio de estatísticas do período colonial, o que significa imprecisões e generalizações, Maryinez Lyons (2002) fez uma estimativa de que apenas em Uganda o número de mortes causadas pela doença do sono ultrapassou a 250.000 vítimas entre 1901 e 1905; enquanto Daniel Headrick (2014) aponta em torno de 200.000. Independente da exatidão, esses relatos apontam que em torno de 2/3 da população fora atingida pela tripanossomíase humana na África.

Pelo envio de 15 missões científicas às coloniais africanas por conta da tripanossomíase, das quais 8 foram britânicas, observamos a importância que essa disputa biomédica obteve no cenário imperial (TILLEY, 2004; 2011). As escolas de Medicina Tropical passaram a ser criadas: Londres e Liverpool (Inglaterra) em 1899; Lisboa (Portugal) em 1902; Marseille (França) em 1905; Bruxelas (Bélgica), 1906; e Amsterdam (Alemanha), 1910 (HEADRICK, 2014). Segundo Maryinez Lyons (1992), a tripanossomíase teve tanto investimento em relação às outras doenças tropicais na proporção que o HIV/AIDS tem hoje para as pesquisas clínico-farmacêuticas nos últimos 30 anos.

Com os projetos da ocupação colonial as doenças tropicais aparecem na forma de barreiras à exploração desejada e o surgimento de ações que aparentavam ser humanitárias, todavia modelavam-se em um enfático racismo (VAUGHAN 1991; HEADRICK, 2014).

Podemos assim classificar essas missões científicas imperiais: a missão francesa segundo os passos de Louis Pasteur e Alphonse Laveran mantiveram-se focado na identificação e eliminação do patógeno; a britânica, com Ronald Ross, Patrick Manson e David Bruce, concentrou-se na teoria dos vetores; a portuguesa, com Annibal Celestino Correia Mendes, Ayres Kopke e Annibal Bettecourt embasavam-se na recuperação do reconhecimento político e científico internacional, como forma de resguardar suas colônias das outras potências; já a alemã, destacaram-se em sua produção químico-farmacológica para a cura; e os belgas, seguindo 
as instruções da Liverpool School of Tropical Medicine e o uso do atoxyl - sistematicamente Ayres Kopke atribuída a si essa descoberta (AMARAL, 2012) - deslocando as populações das regiões infectadas pela mosca do tsé-tsé e os que tinham suspeita de infecção ou infectados do restante da população (HEADRICK, 2014).

Detemo-nos agora na instalação da missão britânica que de forma direta atuou nas regiões da Zâmbia. A Royal Society, de Londres, apoiou o envio da primeira missão de estudo da tripanossomíase a Entebe, Uganda, em 1902. Por indicação de Patrick Manson (1844-1922), dela faziam parte dois de seus alunos, George Carmichel Low (1872-1952), chefe da missão, Aldo Castellani, e ainda Cuthbert Christy (1864-1932), médico da West African Field Force que tinha experiência em outras regiões tropicais. Em março de 1903, chega a Entebe a segunda missão, com David Nunes Nabarro (1874-1958), para substituir Low, David Bruce (1855-1931), que substituía Christy, e Castellani permanecendo lá por mais algum tempo.

$\mathrm{Na}$ Inglaterra, as pesquisas tropicais se iniciaram em um momento em que a medicina tropical assentava-se sobre a investigação laboratorial. Sob a liderança de Patrick Manson a London School of Hygiene and Tropical Medicine foi criada em 1899, que contava com o apoio direto de Joseph Chamberlain (1836-1914), secretário-geral das Colônias, e da Royal Society of London (1663), da qual era membro. Com preocupações sanitaristas, Sir Alfred Lewis Jones e outros proprietários de navios, fundaram em 1899 a Liverpool School of Tropical Diseases, depois renomeada por Liverpool School of Tropical Medicine. Em Portugal, a controvérsia teve início numa época em que a medicina tropical ainda não existia como área científica institucionalizada e a bacteriologia constituía a área por excelência de suporte à medicina experimental.

Qualquer dos intervenientes nessas missões de estudo e também os membros do Comitê de Malária da Royal Society of London eram figuras de referência na história da doença do sono, 
não só do ponto de vista experimental, mas também em relação ao conhecimento dos trópicos. Tinham preparo científico abrangente nos domínios da bacteriologia, parasitologia, história natural, zoologia, fisiologia e histologia, contrastando com o dos médicos portugueses, cuja formação era mais especializada.

Dentre as medidas de controle social adotadas na região do Tanganyika, o poder colonial deslocou em torno de 130.000 pessoas para 70 regiões contornadas por grandes territórios desmatados, como uma forma de impedir o avanço da mosca de tse-tse, até 1934 (HOPPE, 2003). Novamente essas ações coloniais pressupunham que nessas novas realocações, haveria maior disposição e interesse populacional por assimilar traços ocidentais da agricultura e criação de animais, assim quando retornassem a seus locais de origem reproduziriam os ensinamentos ordenando a vida social de forma sadia.

Várias e contínuas tentativas eram feitas para controlar os surtos da tripanossomíase, invadindo os corpos africanos com pulsões e incisões, testagem forçada de medicamentos, realocações das comunidades e o aprisionamento individual ou coletivo como no caso do cordon sanitaire, cuja interrupção da complexidade social causava a desestruturação social e a remodelagem da mobilidade social. No entanto isso não significou uma correspondência absoluta por parte dessas populações. Conforme as estratégias de controle da tripanossomíase alteravam essas estruturas, as populações lidavam com novos riscos e oportunidades. Os que superavam as epidemias, provavelmente, sofriam o rompimento de vínculos sociais - filhos, esposas, esposos, chefes, pais e avós. Esse vínculo social fragilizado pelas medidas preventivas foi desenhando formas de esquiva que seriam observadas na reação às futuras políticas de saúde coletiva no século $\mathrm{XX}$, como no caso do combate ao vírus do HIV (LYONZ, 2002).

Nesse sentido, Hoppe (2003) aponta que a elite local, fazendeiros e pescadores africanos reconheciam que com o controle social de realocações foram inseridas novas variáveis à complexidade de 
relações preexistentes e negociações entre os poderes presentes no espaço social - familiar, de nobres, religiosos e colonial. Para um poder colonial exploratório como no caso do Estado Independente do Congo, o extermínio das comunidades gerava o problema da falta de mão de obra forçada, ocasionando a locomoção de pessoas ou dos postos administrativos para a continuidade da exploração. Por isso, havia a necessidade de negociações contínuas entre o interesse colonial exploratório, médico e missionário e a remodelação da complexidade local, já que o cenário ecológico também estava alterando-se, por mutações de vírus, barragens e desvios hidrográficos, matança de animais de grande porte, desmatamento, prospecção de minérios e aglomerações urbanas.

Por outro lado, os vínculos com as autoridades coloniais e missionárias criavam novas tensões ou ambiguidades sociais, quando esses aparentavam ter algum tipo de refúgio ou proteção ao mesmo tempo em que esses estrangeiros destacam certa repulsa ou desprezo quanto a suas crenças, costumes, línguas e entidades etc.

Pelo apelo da administração colonial, o Escritório Colonial enviou, por meio da Liverpool School of Tropical Medicine, os médicos Allan Kinghorn e Eustace Montgomery.

Dr. Spillane, em 1907, verificou a existência de Glossina Palpalis ao longo do rio Kalungwishi e da mina de Kambove, correspondente hoje à Província de Luapula e Mporokoso. Por receio dos eventos epidêmicos em Congo e Uganda foram tomadas algumas medidas: cortar a mata grossa ao longo das margens do rio Kalungwishi e pouco mais de 270 metros em torno do posto administrativo. Em seguida, efetivou a lei de passe, Pass Ordinance, como feito em 1902 na Rhodésia do Sul. Com um efeito mais drástico para as populações locais foi proibida toda atividade pesqueira, confiscando as canoas da população e as destruindo sem qualquer compensação. Isso provocou um distúrbio social, pois essa era a atividade principal de subsistência da região e interferindo diretamente em sua dieta principal. 
Essa regulamentação rompeu com a rede comercial local extinguindo o comércio de sal, bens de ferro, óleo de palmeira e peixe. Outra consequência foi o rompimento de rituais religiosos. A condução das orações de chuva nos santuários, o culto aos ancestrais e aos chefes, a peregrinação anual aos cultos territoriais de Nsonga ya Chilima na área montanhosa de Kundelungu e de Mwepya a margem leste do lago Mwero. Com receio das penalidades de Nsonga as pessoas tentaram realizar sua peregrinação, porém sendo detidas e multadas.

Outros efeitos coloniais eram o impedimento das visitas missionárias fora ou dentro da área de restrição, abertura de escolas ou capelas, diminuição da força de trabalho nas minas de Katanga, bem como a falta de alimentos para abastecer as construções da administração colonial e a estrada de ferro da Rhodésia.

A população foi realocada em regiões mais altas. Em 1908, os que habitavam Luapula próximo às corredeiras de Nsakaluba, em Kalima, foram deslocadas para Mwense Boma. Da mesma forma aqueles que estavam ao longo do rio Kalungwishi e às margens do lago Mwero foram deslocados para regiões mais altas. Dois anos depois, uma segunda ação de realocação fora feita. Toda a população entre Mwense e o riacho de Mununshi tiveram que ir para Mofwe. E os que restavam a margem de Kalungwishi foram relocados próximos às cascatas de Kundabwika. Para que não houvesse interesse de retorno, foi permitido a eles levarem somente bens de necessidade, deixando criações e plantações para morrerem, apodrecerem ou serem comidos por animais selvagens ou pelos mensageiros coloniais. Suas tendas foram queimadas.

Esperando por eles nessas localidades, salvo algumas exceções que contaram com a ajuda dos moradores locais e dos missionários Plymouth, não tiveram suporte adequado; posto que faltou um plano de realocação mínimo. Isso resultou na morte de muitas pessoas por fome ou outras doenças beneficiárias do organismo 
estressado e mal nutrido. Depois de dois anos, os que sobreviveram a essas novas medidas, conseguiram aproveitar o solo fértil e até conseguiram permissão para pescar.

Até o ano de 1908 a Rhodésia do Norte tinha contratado apenas dois médicos. Com a descoberta da tripanossomíase entre 1907 e 1909, nas regiões de Mwero-Luapula, Kalungwishi, Tanganyika e Luangwa a empresa recrutou mais cinco.

Como notou Dr. H.T. Storrs, médico oficial, em Fort Rosebery, enquanto a restrição da mobilidade social era controlada na Rhodésia, na R.D. Congo os belgas corroboravam o deslocamento da população, observando vária canoas do outro lado do rio.

\section{As Atitudes Elusivas}

Diante da imposição de submissão criavam-se novas vias sociais de interação. Nesse sentido a atribuição de identidades doentias relativas à lepra ou à tripanossomíase gerava a redefinição de novos espaços sociais e vínculos identitários. Ambiguamente esse tipo de atribuição negativa, estigmatizada, oportunizava à população, em casos que os clínicos buscavam alguma informação ou eram abordados incisivamente pelos locais, havia um novo espaço de diálogo que operava ao redor da doença. De um lado era a oportunidade de manifestar suas necessidades, opiniões e preocupações sobre os mais diferentes assuntos à autoridade colonial, de outro, o clínico ouvia e indagava para discriminar o que poderia ser traduzido como relevante a seu diagnóstico. Nesse sentido, a doença era transformada em um meio de comunicação entre a população e a autoridade colonial correspondendo a um tipo de idioma convergente de interesses.

Como descreve Vaughan, "Leprosy offered to the missionaries the possibility of engineering new African communities, isolated from, and expunged of, all those features of African society. In such 
institutions leprosy patients were offered leper identity as a 'liberation'” (1991, p. 78). O tipo de cuidado de seu corpo variava, desde medidas extremamente invasivas como pulsões lombares, no caso da tripanossomíase, medicamentos que os intoxicavam ou matavam, como até poder se tornar assistentes de clínicos, após a cura da predisposição às vicissitudes de sua natureza africana.

Quando as equipes coloniais se aproximavam dos vilarejos, de alguma forma, a população era notificada de antemão; visto que estipulou punições como multas aos que escondiam parentes adoentados ou eles mesmos fugiam para as matas. Essas ações seriam resultado da consciência comunitária em busca de proteção ou cuidado aos seus membros (LYONS, 1992; HUNT, 1999; VAUGHAN, 1991) - embora seja difícil detectar se isso partia de familiares ou qual a posição social do adoentado.

As atitudes elusivas são caracterizadas pela historicidade das relações assimétricas coloniais, segundo as quais a presença do colonizador remetia a diferentes significados de conflitos e de sofrimentos operados no cotidiano. Dessa forma, com a dinâmica de tal operacionalização os significados podiam atrair novos signos ou resíduos de outros conflitos reorganizando-se em novas categorizações de conflitos. Quanto aos resíduos esses eram considerados resultantes de conflitos comunitários, tendo a função de amenizar anseios ou interesses atualizados em comportamentos sociais de esquivas. De outra forma, somente tem essa função social se refletir ou for incorporado em atitudes similares, visto que é legitimado no interior de disposições pré-estabelecidas.

Mesmo que diminuísse pouco os efeitos da dominação colonial sobre o cotidiano, cumpriria com sua função podendo servir a outras situações de imposição. Podemos até observar traços semelhantes dessa mesma dinâmica naquilo que Néstor Canclini (2010) denomina de poder oblíquo em pichações e história em quadrinho na Argentina. Há neste caso certo embate, porém por seu caráter 
de anonimato nas pichações ou de sutileza irônica nas histórias em quadrinho, recontam com a esquiva necessária diante do processo colonizador espanhol sobre seus primeiros habitantes como sobre as populações negras.

Igualmente, esses dispositivos de esquivas operavam para diminuir a pressão de poderes locais sobre determinados territórios. Era o caso da proteção de grupos menores, como Mambwe ou Lala, diante das razias e invasões dos Babemba, ou até do refúgio que mulheres buscavam nas missões contra os maus tratos de seus esposos ou a busca de alimentos durante os períodos de estiagem (KAYAMBI, 1895). Nesse sentido, não devemos, unilateralmente, polarizar entre interesse estrangeiro e sofrimento local, mas desvelar o contexto em que os interesses das populações locais lidavam com determinadas oposições, reproduzindo as relações assimétricas, cuja distinção social pedia outras formas de embate.

O estabelecimento dos missionários em regiões onde a vida social sustentava seus vínculos afetivos se encontrava entre as que a resistência à conversão era presente. Além disso, era comum a associação entre situações novas, alteridades, como a chegada dos estrangeiros e a falta de instrumentais para combater novos estados doentios. O que era evidenciado nos diários dos Missionários da África a fuga de mulheres das aulas de catecismo argumentando que a morte era produzida pelo batismo. Há dois aspectos a serem considerados que por estudos posteriores puderam ser apresentados, como demonstram os estudos de Audrey Richards (1956), Thera Rasing (1994) e Wim van Binsberger (1980), antes da ascensão do poder do chefe supremo Bemba, Chitimukulu, como sendo o detentor de bens simbólicos. Como esses estudos demonstram as mulheres respondiam pelo culto aos antepassados. A partir da crescente expansão territorial Bemba, em 1850, detidos a leste pelos Angoni (migração de grupos Shona em Malauí), os homens resguardaram o culto aos mpashi, culto aos chefes, suplantando o domínio feminino do culto 
dos antepassados comuns. Associado a essa disputa de poder dos cultos dos antepassados e o surgimento de epidemias nas primeiras décadas de 1900, o batismo e/ou ritual de extrema unção aos enfermos convertia-se em causação do mal estar social. Isso produziria o que Luise White (2000) e Gessler (2005) apontou como produção subsaariana de rumores contra as medidas de controle social, interpretadas como estratégia "branca" de roubar sangue das pessoas e produzir remédios a partir deles. Nessa categoria de vampiro estavam autoridades coloniais, missionários cristãos e médicos, juntamente com seus assistentes locais e seus instrumentos como vacinas e vitaminas que até reduziam a fertilidade juvenil.

Em resposta ao domínio do Chitimukulu foi destacado o ritual feminino, chisungu, no cenário social. Com a repercussão da igreja de Lenshina e sua evidência por estudos de gênero, a partir de Audrey Richards (1956) - Calmette, Bisberber e Hinfelaar - a matrilinearidade conseguiu sobrepor-se ao poder do Chitimukulu que havia sido enfraquecido durante o colonialismo da BSAC e na independência em 1964 que centralizava ideologicamente todos os grupos da Rhodésia do Norte em torno do lema de Kennedy Kaunda, "One Zambia, one nation".

O ditado popular inshita ya kushita imyunga panshi (o período em que as espinhas de peixe eram enterradas no chão) foi resultante da proscrição pesqueira de Dr. Spillane. Musambachime afirma ser um ditado comum em toda a extensão de Mwero-Luapula, assegurando a conclusão de sua prática social. Os pescadores que conseguiram esconder suas canoas as usavam a noite para pescar, correndo o risco de morrerem por ataques de crocodilos e hipopótamos. Após comer o peixe, escondido dos mensageiros coloniais (vigias administrativos), enterravam as espinhas na terra.

No mesmo sentido, para as populações que eram removidas de suas terras próximas aos aquíferos, outros rumores apontavam para a arbitrariedade estrangeira. Denunciando esses de quererem reter 
todos os peixes para si bem como usurpar suas terras, principalmente com a chegada dos colonos britânicos (MUSAMBACHIME, 1981).

Alguns chefes em Luapula que criticavam o Acting Administrator, como Nkuba Chisoka, chefe supremo dos Bashila, ao perceber que seria punido pela força militar da NER, juntou seu povo para subirem nas canoas e foram para o outro lado de Luapula, de domínio belga. Para a surpresa da NER, os belgas os receberam e transformaram Nkuba Chisoka em chefe local.

Depois de um ano a lei começou a ser percebida como lei morta em algumas regiões devido a necessidade de mão de obra. Assim foi que Dr. Fleming pressionou o comitê da BSAC para conseguir em torno de sete a dez mil trabalhadores nas minas da Rhodésia do Sul.

Como observamos, as atitudes elusivas foram desdobradas do cenário colonial, de acordo com as tensões ou sobreposições das autoridades estrangeiras. Dentre as várias maneiras de esquivas encontradas há as que permeavam o cotidiano como ausente, quando a população evitava uma confrontação aberta com receio de algum tipo de punição, porém a exercendo longe dos olhos das autoridades - como o caso da pesca a noite -; as atitudes de adoção do mundo estrangeiro como um refúgio às incertezas sociais na forma de negação de si e de sua historicidade, exemplificado pela posição de mensageiros coloniais ou catequistas; e, outras atitudes, como dito por Gessler de rumores que embora às autoridades conhecessem e tentassem combater não operavam no interior de uma mesma lógica, por sua estruturação assimétrica.

Sem um interesse de esgotar todas as expressões de atitudes elusivas, observamos que a dinâmica entre fatores ecológicos/ mobilidade humana, interesses coloniais tanto pela exploração das riquezas naturais e força de trabalho aliados ao desenvolvimento da medicina tropical e as respostas da população dentro de estruturas 
assimétricas possibilitam elucidar novas formas de entendimento a respeito da chamada resistência populacional, quanto a não adesão a determinadas campanhas de saúde, compreendendo-as como pertencentes a novas produções de controle social.

\section{Considerações Finais}

$\mathrm{O}$ argumento de Maryinez Lyons que, segundo a autora, em suas pesquisas de campo as populações apontaram a causa da epidemia de tripanossomíase ter sido do processo de deterioração social imposto pelos estrangeiros. As migrações continuaram e continuam e temos a impressão de que em toda a região norte da Rhodésia do Norte e no Forte Jameson, de acordo com as tradições de noivado e pagamento de dote não haver menção do pagamento em gado, nem de rituais relativos à procriação desse paquiderme, como observamos entre os Tonga ao Sul (CLIGGETT, 2013). Isso sugere que a nagana bem como tripanossomíase humana não terem sido introduzidas pela chegada do colonialismo, quiçá das rotas árabes em busca de escravos. Por outro lado, seria uma condição ecológica endêmica, não diferenciada em rituais pela busca de cura para malária ou outra situação da hematúria. Por isso, a interrupção dos tratamentos sem fornecer-lhes condições de realocação adequada ou indenização, mas impondo-lhes o uso de sua força de trabalho nas minas de prospecção. Outrossim, os interesses externos reproduziram as condições de vulnerabilidade de longa duração.

Propusemos lançar novas reflexões sobre os efeitos sociais da exploração pré-colonial e colonial no interior da África Central tendo como foco a região próxima ao rio Kalungwishi no norte da Zâmbia e do Forte Jameson no Malauí. Foram as várias ações de interesse estrangeiro que impuseram sobre as populações locais situações de vulnerabilidade de longa duração, geradoras da exploração de riquezas africanas por interesses externos. Foram esses interesses 
que buscamos elucidar por meio da dinâmica do processo colonizador, interpretados pela interação das três dimensões, ecológica, da Medicina Tropical e das operacionalizações africanas. Diante dessas contínuas imposições as populações conseguiram a partir de suas práticas culturais desenvolver posicionamentos políticos de oposição denominados aqui de atitudes elusivas.

Dessa forma, o estudo das atitudes elusivas podem explorar os efeitos da exclusão social delineantes de situações de vulnerabilidade perdurados em várias gerações. Para que as políticas públicas tenham a eficácia desejada na salvaguarda de sua população, e não de controle dos seus corpos e de sua alteridade, essa proposição investigativa de longa duração debruça-se sobre o intercâmbio de dimensões do cotidiano tratadas isoladamente. Nesse sentido, o reconhecimento do poder político de populações em exclusão procura criar um espaço de diálogo por meio de idiomas estabelecidos, como foi o caso da tripanossomíase, entre medidas preventivas e práticas culturais como resultado de uma lógica social de longa duração. $\mathrm{O}$ que pode ser observado por rumores de vampirismo, manutenção da iniciação feminina, culto aos antepassados, pescas de madrugada e funções coloniais assimilativas (catequistas, religiosos, mensageiros e outros) que por constantes migrações mantiveram dispositivos culturais em larga escala e por várias gerações.

\section{Referências Bibliográficas}

AMARAL, I. Bactéria ou parasita? a controvérsia sobre a etiologia da doença do sono e a participação portuguesa, 1898-1904. História, Ciência e Saúde-Maguinhos, vol. 19, n. 4, out-dez/2012. Disponível em: < http://www.scielo.br/scielo.ph p?pid=S0104-59702012000400010\& script=sci_arttext $>$. Acesso em: 13/06/2012. BINSBERGER, W. Religious change in Zambia: exploratory studies. London/ Boston: Kegan Paul, 1981. 
CANCLINI, N. G. Culturas híbridas: entrar e sair da modernidade. São Paulo: EDUSP, 2010.

CLIGGETT, L. Componentes sociais da migração: experiências da província sul, Zâmbia. Revista História Questões e Debates, 58: 2013. Disponível em: < http:// ojs.c3sl.ufpr.br/ ojs/index.php/historia/ article/view/33872>. Acesso em: 10/1/2014.

COMAROFF, J; COMAROFF, J. Ethnography and the historical imagination. E.U.A., Boulder, Westview: 1992.

CORBEIL, J.J. Mbusa: sacred emblems of the Bemba. Mbala, Moto-Moto Museum; London: Ethnographica Publishers: 1982.

CUNNISON, I. (trans.). King Kazembe: Gamitto's diary of the Portuguese expedition 1831-2. Lisbon, Junta de Investigações do Ultramar: 1960.

DA SILVA, J. O. A dupla sondagem para interpretar as narrativas missionárias católicas na Zâmbia. Revista Eletrônica do Tempo Presente, ano 3, n. 3, 2012a. Disponível em: $<$ http://www.tempopresente.org/index.php?option=com content\&view=article \&id=5855:a-dupla-sondagem-para-interpretar-as-narrativas-missionarias-catolicas-na-zambia\&catid=92:edicao-do-mes-de-setembro2013\&Itemid=226>. Acesso em: 10/03/2012.

A autonomia kantiana e o enredo da exclusão: análise das condições sócio-históricas brasileiras geradas pelo processo colonizador. Revista Bioética, vol. 20, n. 1. 2012b. pp. 87-96.

DECCA, E. S. 1930 - O silêncio dos vencidos. 2a. ed. Rio de Janeiro: Brasiliense, 2004. DE HEUSCH, L. (1972) Le roi ivre ou l'origine de l'état. Paris, Gallimard: 1972. Rois nés d'un coeur de vache. Paris, Gallimard:1982.

ECHENBERG, M. Black death, white medicine: bubonic plague and the politics of public health in colonial Senegal, 1914-1945. EUA, Heinemann: 2002.

ELERT, H. The magic of Makishi: masks e traditions in Zambia. Singapore, Tien Wah Press: 200?.

EPSTEIN, Arnold Leonard. Military organization and the pre-colonial of the Bemba of Zambia. Man, Vol. 10, n. 2, p. 199-21, jun. 1975. Disponível em: <http://www. jstor.org/stable/2800494>. Acesso em: 15 mar. 2011.

FANON, F. Máscaras brancas e pele negra. Salvador, EDUFBA: 2010.

GARREC. Lubemba of the years 1910-1920 seen through the writings of Fr Garrec WF, 1910-1920 (?) 
GEISSLER, P. W.; POOL, R.. Editorial: Popular concerns about medical research projects in sub-Saharan Africa - a critical voice in debates about medical research ethics. Tropical Medicine and International Health, vol. 11, n. 7, pp. 1-8.

GAUSSET, Q. Etude préliminaire des Wawa de l'Adamawa (Cameroun). Mémoire de Licence, Université Libre de Bruxelles: 1992.

GOSSELAIN, O. In pots we trust: the processing of clay and symbols in sub-Saharan Africa. Journal of Material Culture, vol. 4, n. 2, p. 205-230, jul. 1999.

IPENBURG, A. 'All good men': the development of Lubwa mission, Chinsali, Zambia, 1905-1967. New York, Peter Lang: 1992.

HEADRICK, D. Seeping sickness epidemics and colonial response in East and Central Africa. - 1900-1940. PLoS Neglected Tropical Disease, 8(4): 2004. e2772.2014 HOPPE, K. A. Lords of the fly: sickness control in British East Africa, 1900-1960. Connecticut, Praeger: 2003.

HUNT, N. R. A colonial lexicon of birth ritual, medicalization, and mobility in the Congo. EUA, Duke University Press: 1999.

KALINGA, O. J. M. Colonial rule, missionaries and ethnicity in the north Niassa District (1891-1938). African Studies Review, vol. 28, n.1, p. 57-72, mar. 1985. Disponível em: <http://www.jstor.org/stable/524567>. Acesso em: 15 abr. 2011.

KAYAMBI. Diário de posto missionário. Lusaka, Faith and Encounter Centre: 1900-1911.

LÉPINE, C. Os dois reis do Danxome: varíola e monarquia na África Ocidental, 1650-1800. São Paulo, Marília, Cultura Acadêmica Editora: 2000.

LABRECQUE, Edouard. Beliefs and religious practices of the Bemba and neighbouring tribes. Zâmbia, Chinsali: Language Centre Ilondola. [1a. Parte 1931, 2a. parte 1934], 1982.

\section{LINDEN; LINDEN}

LYONS, M. The colonial disease: a social history of sleeping sickness in northern Zaire, 1900-1940. Cambrige, Cambridge University Press: 1992.

MACKENZIE, J. (1984), em Propaganda and Empire: the manipulation of British Public Opinion, 1880-1960. :1984.

M'BOKOLO, E. África Negra: história e civilizações. Do século XIX aos nossos dias. Tomo II. Porto: Edições Colibri, 2007.

MPONDA-MAMBWE. Diário de posto missionário. Lusaka, Faith and Encounter Centre: 1891-1905; 1891-1895. 
MUSAMBACHIME, M. The social and economical effects of sleeping sickness in Mweru-Luapula - 1906-1922. African Economic History, n. 10, 1981, pp. 151-173.

NASCIMENTO, W. F.; MARTORELL, L. B. A bioética de intervenção em contextos descoloniais. Revista Bioética, vol. 21, n. 3. 2013. pp. 423-431.

OLIVER, Roland; ATMORE, Anthony. Medieval Africa-1250-1800. EUA, Nova Iorque: Cambridge University Press, 2001.

OSTERHAMMEL, Jürgen. Colonialism: a theoretical overview. 2a. ed. E.U.A., Princeton: Markus Wiener Publication, 2005.

PACKARD, R. M. White palgue, black labor: tuberculosis and the political economy of health and disease in South Africa. California, University of California Press: 1989.

PEREIRA; RIBAS, 2012

RASING, Thera. Passing on the rites of passage : girls' initiation rites in the context of an urban Roman Catholic Community on the Zambian Copperbelt. Leiden, Holanda: African Studies Centre Series 6/1995, 1996.

RENAULT, Fançois. Le Cardinal Lavigerie, 1825-1892. França, Paris, Fayard : 1992.

RICHARDS, Andrey. Chisungu: a girl's initiation ceremony among the Bemba of Northern Rhodésia. London: Longman: 1956.

ROBERTS, Audrey. A history of the Bemba: political growth and change in NorthEastern Zambia before 1900. London: Longman, 1973.

ROSENBERG, C. E; GOLDEN, J. (eds.). Framing disease: studies in cultural History. New Jersey, Rutgers University Press: 1997. (intro.)

ROSENBERG, C. E. Explaining epidemics and other studies in the History of Medicine. Cambridge, Cambridge University Press: 1992.

SCOTT, H. A history of Tropical Medicine. Baltimore, Williams and Wilkins: 1947. pp. 454-480; 513-523.

SCOTT, J. Weapons of the weak. - everyday forms of peasant resistence. New Haven, Yale University Press: 1985.

THOMPSON, E. E. The making of English working class. Londres, Penguin: 1968. TILLEY, H. Ecologies of complexity: Tropical environments, African trypanosomiasis, and the

science of disease control in British colonial Africa, 1900-1940. Osiris 19: 2004. pp. 21-38. 
. Africa as a living laboratory. Chicago, University of Chicago Press: 2011. pp. 176- 191

VANSINA, Jan. Kingdoms of savanna. Madison, University of Madison:1985. . Paths in the rainforests. Londres, James Currey: 1990.

. Linguistic Evidence for the Introduction of Ironworking into BantuSpeaking Africa; vol. 33, p. 321-36, 2006. Disponivel em: <http://www.jstor.org/ stable/20065776>. Acesso em: 28 fev. 2006.

VAUGHAN, M. Curing their ills: colonial power and African illness. California, Stanford: 1991.

WHITE, Luise. Speaking with vampires:rumors and History in Colonial Africa. California, University of California Press: 2000.

WITKAMP, B. Seeing makishi - an anthropological study of a west Zambian art. M.A. Thesis. University of Leiden, Netherlands: 1987.

Enviado em 20 de agosto de 2015

Aprovado em 30 de outubro de 2015 